\title{
PP-10 induces apoptosis via JNK/SPAK activation and STAT3 inhibition in Hepatocarcinoma cells in vitro
}

\author{
Ziyi $\mathrm{AN}^{1}$, Peiyan $\mathrm{HE}^{2}$, Guocai WANG ${ }^{3}$, Gexiu LIU ${ }^{*}$, Jianwei JIANG²*
}

\begin{abstract}
Background: The detail of mechanism involving in PP-10 anti-cancer activity remains to be elucidated, and the effect on HCC cells is unknown. Methods: MTT and colony formation assays were used to determine the effect of PP-10 on cell growth. Flow cytometry analysis and Hoechst 33258 were used to assess apoptosis. Gene set enrichment analysis (GSEA) was used to explore changes in apoptosis-associated pathways. Western blotting was used to detect protein expression levels. Results: In our study, PP-10 significantly suppressed cancer cell viability while had low toxicity to normal cells, with the HCC cell lines HepG2 and $\mathrm{HuH7}$ being particularly sensitive to PP-10 treatment. PP-10 induced mitochondrial-related apoptosis in HepG2 and HuH7 cells. Moreover, GSEA showed that the MAPK signaling pathway could be correlated with PP-10-induced apoptosis. We used western blotting to confirm that PP-10 induced apoptosis in HepG2 and HuH7 cells by modulating the JNK/SPAK signaling and inhibiting the STAT3 signaling pathway. Conclusion: Collectively, our results show that PP-10 induces apoptosis via the JNK/SPAK and STAT3 signaling pathways in HepG2 and HuH7 hepatocarcinoma cells.
\end{abstract}

Keywords: PP-10; hepatocarcinoma; apoptosis; JNK/SPAK; STAT3.

Practical Application: PP-10 may be a promising agent for the treatment of liver cancer.

\section{Introduction}

Primary liver cancer is the second leading cause of cancerrelated death worldwide and is therefore a major public health challenge. Primary liver cancer includes hepatocellular carcinoma (HCC), intrahepatic cholangiocarcinoma, and other rare tumors that together account for more than $90 \%$ of patients with hepatocellular carcinoma (Sia et al., 2017). Due to the lack of early clinical symptoms, HCC is often diagnosed at advanced stages (Hao et al., 2019). In 2012, approximately 782,000 cases were diagnosed and there were 746,000 deaths associated with HCC worldwide (Forner et al., 2018). Chemotherapy is among the most important treatments for advanced HCC (Ikeda et al., 2018). However, although chemotherapeutic drugs are effective in treating advanced HCC, they have low susceptibilities to advanced HCC and lead to serious side effects. Moreover, patients treated with single or combination chemotherapy are prone to relapse and tumors can develop drug resistance. Therefore, it is of great urgency to discover a new effective drug with few side effects for the treatment of HCC.

Traditional Chinese medicines (TCMs) contain a wide variety of natural bioactive compounds and show therapeutic anti-cancer effects (Yan et al., 2017). Compared with traditional chemotherapy drugs, TCMs are less toxic, causing fewer side effects, and are relatively inexpensive. (Mostafa et al., 2021; Wang \& Jin, 2021; Morales-Ávila et al., 2020) TCMs have been combined with various conventional clinical therapies to treat HCC and may enhance tumor sensitivity to radiotherapy and chemotherapy, reduce toxicity and side effects, and improve the quality of life and survival rate of patients (Ling et al., 2018).

The dry root of the of Paris polyphylla Var. Yunnanensis (Franch.) Hand. - Mazz and the leaves and flower of Paris polyphylla var. Chinensis (Franch.) Hara are widely available in China (Song et al., 2017). Paris polyphylla contains steroidal saponins that exhibit various pharmacological activities such as potential antitumor effects, anti-inflammatory properties, and may aid in regulation of the immune system (Liang et al, 2019). Paris polyphylla is widely used in folk medicine for its anti-tumor effects to treat lung cancer, nasopharyngeal carcinoma, brain tumors and excretory system tumors. Here, we explored the molecular mechanism of PP-10, a compound isolated from Paris polyphylla var. yunnanensis that inhibits the proliferation of human HCC cells. We show that PP-10 induces apoptosis mainly by activating JNK/SPAK and blocking STAT3 signaling pathways. Our study demonstrates that PP-10 is a promising drug with anti-tumor activity in HepG2 and HuH7 human HCC cells. 


\section{Material and methods}

\subsection{General experimental procedures}

JASCO FT/IR480 plus FTIR spectrometer (JASCO, Tokyo, Japan) was used to measure the IR spectra. Using a JASCO V-550 UV/ VIS spectrophotometer (JASCO) to record the UV spectra, and optical rotations were measured by a JASCO P-1030 automatic digital polarimeter (JASCO). ESIMS data were obtained with a Finnigan LCQ Advantage Max mass spectrometer (Thermo Electron Corporation, MA), and HRESIMS data were measured by an Agilent 6210 ESI/TOF mass spectrometer (Agilent Technologies, CA). Using a Bruker AV-400 spectrometer (Bruker Corporation, Faellanden, Switzerland) to obtain the 1D and 2D NMR spectra, with tetramethylsilane (TMS) as an internal standard. Analytical HPLC was performed using chromatography (Waters, Milford, MA) equipped with an evaporative light-scattering detector, a P680 pump, and a $\mathrm{C}_{18}$ reversed phase column (Cosmosil, $5 \mu \mathrm{m}, 4.6 \mathrm{~mm} \times 250 \mathrm{~mm}$; Nacalai Tesque, Inc., Kyoto, Japan). Preparative HPLC was performed by a Varian chromatography instrument with a Prostar 215 pump, a Prostar 325UVVIS detector, and $\mathrm{a}_{18}$ reversed-phase column (Cosmosil, $5 \mu \mathrm{m}$, $10 \mathrm{~mm} \times 250 \mathrm{~mm}$, Nacalai Tesque, Inc.). Column chromatography (CC) was performed using silica gel (200-300 mesh; Qingdao Marine Chemical, Inc., Qingdao, China), macroporous resin (Diaion HP-20), ODS silica gel (50 $\mu \mathrm{m}$; YMC), and Sephadex LH-20 (Pharmacia Biotech Corporation, Sweden). Silica gel $\mathrm{GF}_{254}$ plates (Yantai Chemical Industry Research Institute, Yantai, China) were used for thin-layer chromatography.

\subsection{Materials}

The dried roots of Paris polyphylla var. yunnanensis were collected in February 2009 in Yunnan Province, China. The species was identified by Prof. Guang-Xiong Zhou (College of Pharmacy, Jinan University). A voucher specimen (No. 20090226) was deposited at the Institute of Traditional Chinese Medicine and Natural Products, Jinan University, Guangzhou.

\subsection{Extraction and isolation}

Air-dried and powdered roots of $P$. polyphylla var. yunnanensis $(10 \mathrm{~kg})$ were extracted with $70 \%$ ethanol at room temperature. The solution was concentrated under reduced pressure to produce a residue $(1.5 \mathrm{~kg})$ that was then suspended in water and filtered. The filtrate was loaded onto a Diaion HP-20 column and chromatographed using an $\mathrm{EtOH} / \mathrm{H}_{2} \mathrm{O}$ (30:70, 60:40, 95:5, v/v) solvent system. The $95 \% \mathrm{EtOH}$ fraction $(550.0 \mathrm{~g})$ was separated by silica gel column chromatography $\left(\mathrm{CHCl}_{3} / \mathrm{MeOH}, 100: 0\right.$ to $0: 100, v / v)$ to give fourteen subfractions $(1-14)$. Fraction 10 was separated by preparative HPLC $\left(\mathrm{MeOH} / \mathrm{H}_{2} \mathrm{O}, 75: 25, v / v\right)$ to yield compound PP-10 (66.3 mg).

Analytical data for PP-10:White amorphous powder, [a] ${ }^{25}-91.0^{\circ}\left(c 0.71, \mathrm{C}_{5} \mathrm{H}_{5} \mathrm{~N}\right)$; IR (KBr) $v_{\text {max }}: 3408,2950,2875$, 1647, 1453, 1376, 1130, 1049, 984, $902 \mathrm{~cm}^{-1}$; ESI-MS m/z: $1467.5[2 \mathrm{M}+\mathrm{Na}]^{+}, 745.6[\mathrm{M}+\mathrm{Na}]^{+} ;{ }^{1} \mathrm{H} \mathrm{NMR}\left(400 \mathrm{MHz}, \mathrm{C}_{5} \mathrm{D}_{5} \mathrm{~N}\right)$ $\delta_{\mathrm{H}}: 6.39\left(1 \mathrm{H}\right.$, brs, $\left.\mathrm{H}^{\prime \prime}{ }_{\text {rha }}-1\right), 5.32(1 \mathrm{H}, \mathrm{m}, \mathrm{H}-6), 5.05(1 \mathrm{H}, \mathrm{d}, J=$ $\left.7.1 \mathrm{~Hz}, \mathrm{H}^{\prime}{ }_{\text {glc }}-1\right), 1.78\left(3 \mathrm{H}, \mathrm{d}, J=6.2 \mathrm{~Hz}, \mathrm{H}^{\prime \prime}{ }_{\text {rha }}-6\right), 1.15(3 \mathrm{H}, \mathrm{d}, J=$ 6.9 Hz, H-21), 1.07 (3H, s, H-19), 0.84 (3H, s, H-18), 0.70 (3H, $\mathrm{d}, J=5.5 \mathrm{~Hz}, \mathrm{H}-27) ;{ }^{13} \mathrm{C}$ NMR $\left(100 \mathrm{MHz}, \mathrm{C}_{5} \mathrm{D}_{5} \mathrm{~N}\right) \delta_{\mathrm{C}}: 140.9$ (C5), 121.7 (C-6), 109.3 (C-22), $102.1\left(\mathrm{C}^{\prime \prime}{ }_{\mathrm{rha}}-1\right), 100.4\left(\mathrm{C}_{\mathrm{glc}}^{\prime}-1\right)$, 81.1 (C-16), $79.7\left(\mathrm{C}_{\mathrm{glc}}^{\prime}-2\right), 78.3(\mathrm{C}-3), 78.0\left(\mathrm{C}_{\mathrm{glc}}^{\prime}-5\right), 77.9\left(\mathrm{C}_{\mathrm{glc}}^{\prime \mathrm{glc}}-3\right)$, $74.2\left(\mathrm{C}_{\text {rha }}^{\prime \prime}-4\right), 72.9\left(\mathrm{C}_{\text {rha }}^{\prime \prime}-3\right), 72.6\left(\mathrm{C}_{\text {rha }^{\prime \prime}}-2\right), 71.9\left(\mathrm{C}_{\mathrm{glc}^{\prime}}-4\right)$, $69.5\left(\mathrm{C}^{\prime \prime}{ }_{\text {rha }}-5\right), 66.9(\mathrm{C}-26), 62.9(\mathrm{C}-17), 62.7\left(\mathrm{C}_{\mathrm{glc}}^{\prime}-6\right), 56.7(\mathrm{C}-$ 14), 50.3 (C-9), 42.0 (C-20), 40.5 (C-13), 39.9 (C-12), 39.0 (C-4), 37.5 (C-1), 37.2 (C-10), 32.3 (C-15), 32.2 (C-7), 31.8 (C-23), 31.7 (C-8), 30.6 (C-25), 30.2 (C-2), 29.3 (C-24), 21.1 (C-11), 19.4 (C-19), 18.7 ( $\left.\mathrm{C}_{\text {rha }}^{\prime \prime}-6\right), 17.3$ (C-27), 16.3 (C-18), 15.0 (C-21).

The spectral data showed that compound PP-10 (Figure 1A) and $(3 \beta, 25 R)$-spirost-5-en-3-ol 3-O- $\alpha$-l-rhamnopyranosyl- $(1 \rightarrow 2)$ $\beta$-d-glucopyranoside has the same structure. ${ }^{12}$

\subsection{Drugs and reagents}

PP-10 was isolated from Paris polyphylla var. yunnanensis as described above and was kindly provided by the Institute of Traditional Chinese Medicine and Natural Products, Jinan University. A 100-mM stock solution in DMSO (Sigma-Aldrich, Shanghai, China) was prepared and stored in the dark at $-20^{\circ} \mathrm{C}$. A $1000 \mathrm{mM}$ working solution was prepared by diluting with phosphate buffer saline (PBS) for cell culture experiments and was stored at $4{ }^{\circ} \mathrm{C}$. High-glucose Dulbecco's modified Eagle's medium (HG-DMEM), Rowell Park Memorial Institute (RPMI) 1640 medium and penicillin-streptomycin were purchased from HyClone Laboratories (Logan, UT). Fetal bovine serum (FBS) and trypsin were purchased from Gibco (Grand Island, NY). 3-(4, 5-Dimethyl-2-thiazolyl)-2, 5-diphenyl-2-H-tetrazolium bromide (MTT) was purchased from Sigma. Annexin V-FITC/PI apoptosis detection kits and a mitochondrial membrane potential detection kit (JC-1) were purchased from KeyGen BioTECH (Nanjing, China). Hoechst 33258 was purchased from Solarbio (Beijing, China). Antibodies against caspase-3, caspase-9, cleaved caspase-3, cleaved caspase-9, PARP, cleaved PARP, Bcl-2, BclxL, Bak, Bax, GAPDH, c-Myc, Mcl-1, CyclinD1, c-JNK, signal transducers and activators of transcription 3 (STAT3), p-STAT3, p-ERK, p-p38, p-JNK and c-JUN were purchased from Cell Signaling Technology (Boston, MA).

\subsection{Cell lines and cell cultures}

Human HCC cell lines (HepG2, HuH7, QGY-7703, Hep 3B, SMMC-7721), breast cancer cell lines (MDA-MB-468, MDAMB-231), the cervical cancer cell line Caski, and the immortalized normal human hepatic cell line LO2 were obtained from the Department of Biochemistry, Jinan University. The HCC cells, breast cancer cells and cervical cancer cells were maintained in HG-DMEM medium with $10 \%$ FBS containing $100 \mathrm{U} / \mathrm{mL}$ penicillin-streptomycin solution. LO2 cells was cultured in RPMI 1640 with $10 \%$ FBS and $100 \mathrm{U} / \mathrm{mL}$ penicillin-streptomycin. All cell lines were separately incubated at $37^{\circ} \mathrm{C}$ with $5 \% \mathrm{CO}_{2}$ and regularly checked for mycoplasma contamination. When the cells grew to $80 \%-90 \%$ confluence, they were trypsinized and passaged every 3 days.

\subsection{Cell viability assay}

The effect of PP-10 on cell viability was measured using the MTT assay. Briefly, a cell suspension $\left(6.5 \times 10^{4} / \mathrm{mL}\right)$ was seeded 
A

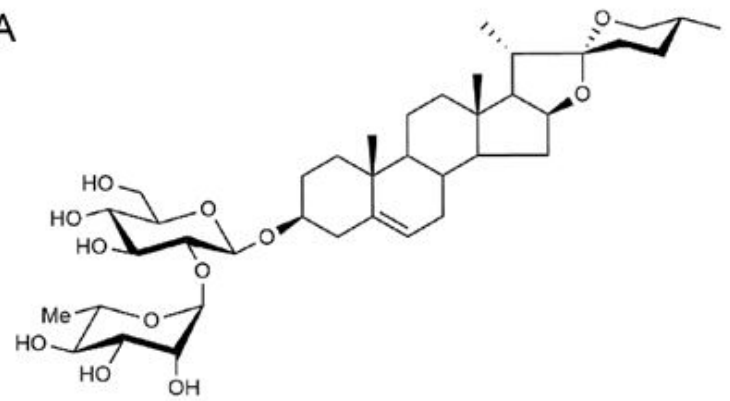

C

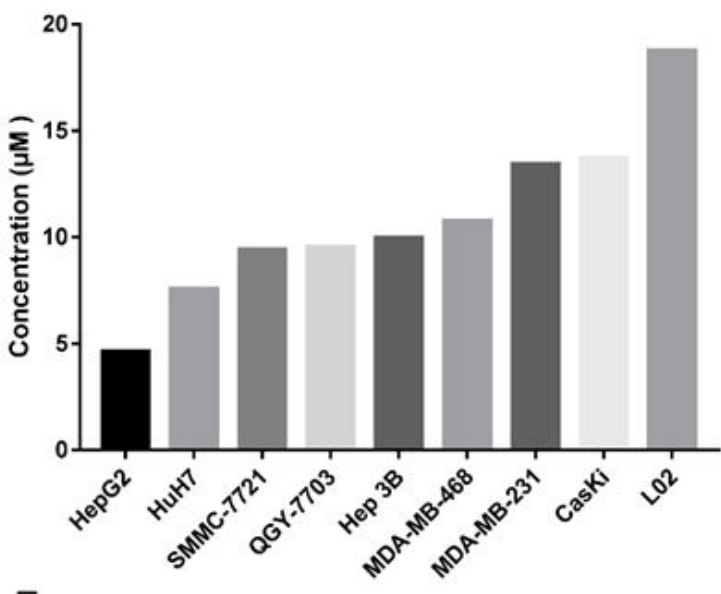

$\mathrm{E}$

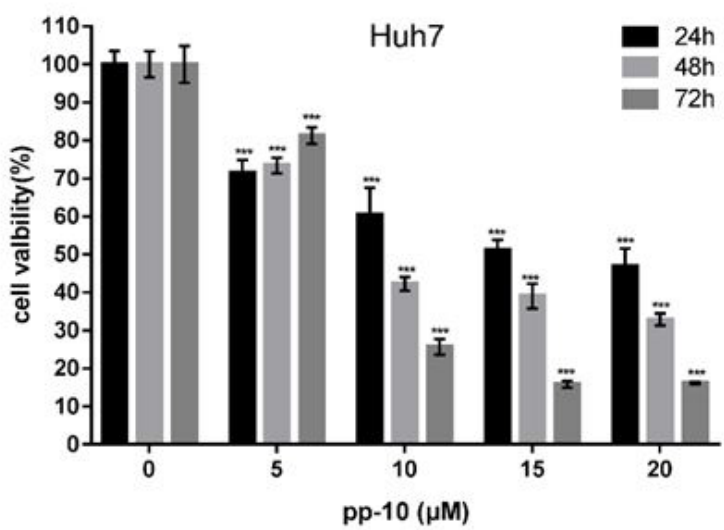

B
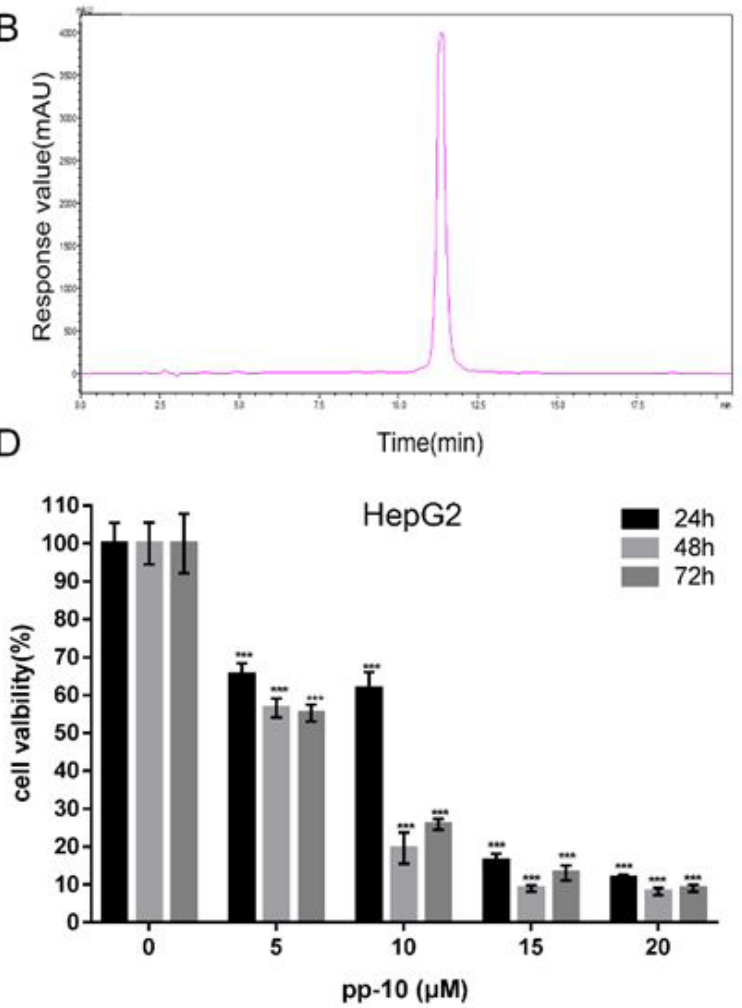

$\mathrm{F}$
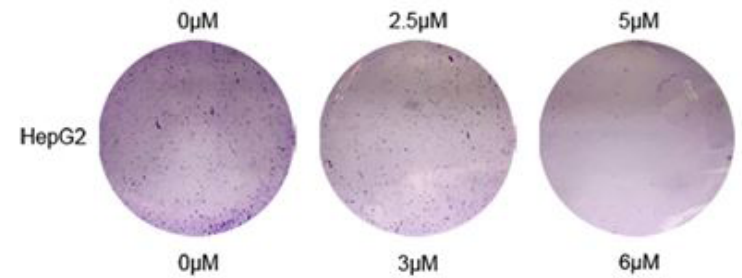

$6 \mu \mathrm{M}$
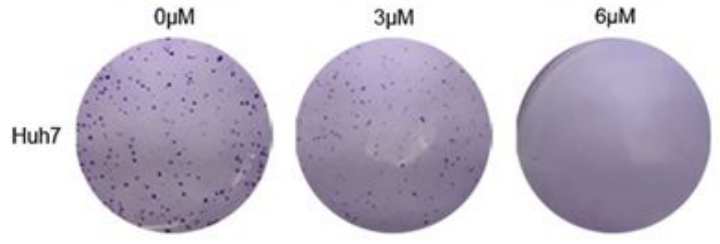

Figure 1. PP-10 inhibits hepatocellular carcinoma cells proliferation. (A) the chemical structure of PP-10. (B) Compound PP-10 was analyzed by the analytical $\mathrm{HPLC}\left(\mathrm{CH} 3 \mathrm{OH} / \mathrm{H} 2 \mathrm{O} / \mathrm{CH} 3 \mathrm{COOH}, 85: 15: 0.01,1656.35 \mathrm{psi}, 25^{\circ} \mathrm{C}, 210 \mathrm{~nm}\right)$. The purity of compound PP- 10 over $95 \%$. (C) IC50 of PP-10 for various cancer cells and normal cell. Cancer cells, including the human hepatocellular carcinoma cells (HepG2, HuH7, QGY-7703, Hep3B, SMMC-7721), breast cancer cells (MDA-MB-468, MDA-MB-231), cervical cancer cell Caski. And immortalized normal human hepatic cell line LO2. (D-E) The HepG2 and Huh7 cells were cultured in medium with PP-10 $(0,5,10,15,20 \mu \mathrm{M})$ for $24,48,72 \mathrm{~h}$, and cell viability was measured by MTT. The results were express as the means \pm SD of three independent experiments. ${ }^{*}$ compared with control group,$p<0.05$; $* *$ compared with control group $p<0.01$; $^{* *}$ compared with control group $p<0.0019$ (Two way ANOVA). (F) Colony formation assay. The HepG2 and Huh7 cells were treated with indicated doses of PP-10. The clones were visualized by crystal violet staining. HPLC: high performance liquid chromatography; MTT: 3-(4, 5-dimethyl-2-thiazolyl)-2, 5-diphenyl-2-H-tetrazolium bromide: IC50, half maximal inhibitory concentration.

in 96-well plates. After incubation for $24 \mathrm{~h}$, the cells were either treated with serial concentrations of PP-10 for $48 \mathrm{~h}$, or treated for various durations $(0,24,48,72 \mathrm{~h})$. After treatment, MTT solution $(20 \mu \mathrm{L})$ was add to each well, the samples were incubated at $37^{\circ} \mathrm{C}$ for $4 \mathrm{~h}$, then the absorbance was measured at $490 \mathrm{~nm}$.

\subsection{Colony formation assay}

HepG2 and HuH7 cells were seeded into 6-well plates at a density of 1000 cells per well and incubated in HG-DMEM medium overnight. The cells were then treated with PP-10 at the indicated 
concentrations until the cells grew to visible colonies (about 14 days). Cell colonies were fixed with $4 \%$ paraformaldehyde and stained with crystal violet solution for 30 minutes. The stained colonies were photographed using a digital camera.

\subsection{Hoechst 33258 staining assay}

HepG2 and HuH7 cells $\left(2 \times 10^{5}\right)$ were treated with PP- 10 at the indicated concentrations for $24 \mathrm{~h}$. The cells were washed with PBS and fixed with $4 \%$ paraformaldehyde for 30 minutes, washed again with PBS, and stained with $500 \mu \mathrm{L}$ Hoechst $33258(10 \mu \mathrm{g} /$ $\mathrm{mL}$ ) for $10 \mathrm{~min}$ at $37^{\circ} \mathrm{C}$. The cells were then again washed with PBS and detected using a fluorescence microscope (Bio-TEK, Winsooki, VT).

\subsection{Apoptosis analysis using flow cytometry}

HepG2 and HuH7 cells $\left(2 \times 10^{5}\right)$ were treated with PP10 at the indicated concentrations for $24 \mathrm{~h}$, then harvested and washed with PBS three times. Annexin V-FITC $(10 \mu \mathrm{L})$ and PI $(5 \mu \mathrm{L})$ were added to the cells and incubated for $15 \mathrm{~min}$ at room temperature in the dark. The cells were then suspended in staining buffer $(200 \mu \mathrm{L})$ and immediately analyzed using a flow cytometer (Becton, Dickinson and Company, Franklin Lakes, NJ).

\subsection{Mitochondrial membrane potential assay}

HepG2 and HuH7 cells $\left(2 \times 10^{5}\right)$ were treated with PP10 at the indicated concentrations for $24 \mathrm{~h}$, then harvested and washed three times with PBS. JC-1 staining solution $(200 \mu \mathrm{L})$ was added to the cells and incubated for $15 \mathrm{~min}$ at $37^{\circ} \mathrm{C}$ in a $\mathrm{CO}_{2}$ incubator, then the cells were analyzed by flow cytometry. The mitochondrial membrane potential was measured using the FL-2 channel and green fluorescence was measured using the FL- 1 channel.

\subsection{Total RNA extraction and next-generation RNA sequencing}

Total RNA was extracted from the HepG2 and HuH7 control group and drug treatment groups using TRIzol reagent (Invitrogen) following the manufacturer's instructions. RNA sequencing of the control group and drug treatment cells was conducted using the BGIseq-500 platform (BGI, Shenzhen, China). Gene set enrichment analysis (GSEA) was carried out using GSEA v3.0.

\subsection{Western blotting}

HepG2 and HuH7 cells $\left(2 \times 10^{5}\right)$ were treated with PP-10 at the indicated concentrations for $24 \mathrm{~h}$, then washed with PBS and lysed in radioimmunoprecipitation assay buffer on ice for $30 \mathrm{~min}$. The total protein extract was centrifuged at $13000 \times$ $g$ for $10 \mathrm{~min}$ and total protein was determined by the BCA assay (KeyGen BioTECH). The protein sample $(30 \mu \mathrm{g})$ was separated by $10 \%-15 \%$ sodium dodecyl sulfate-polyacrylamide gel electrophoresis, electro-transferred onto a polyvinylidene fluoride membrane, then blocked with 5\% non-fat milk for $60 \mathrm{~min}$ at room temperature and incubated with primary antibodies overnight (1:1000 dilution) at $4{ }^{\circ} \mathrm{C}$. Next, the membranes were washed three times with TBST buffer and incubated with horseradish peroxidase-conjugated secondary antibodies at room temperature for $60 \mathrm{~min}$. After washing three times with TBST, the membrane was covered with ECL luminescent liquid and the protein bands were visualized using a Gel Image System (UVItec Ltd., Cambridge, UK) to quantify the intensity of each protein band.

\subsection{Statistical analysis}

All data are presented as the mean \pm SD of at least three independent experiments. All statistical analyses were carried out with GraphPad Prism Version 5 (GraphPad Software Inc., San Diego, CA) with independent-sample $t$-test, one-way ANOVA, and two-way ANOVA. A $p$ value $<0.05$ was consideration to be statistically significant.

\section{Results}

\subsection{PP-10 inhibits sensitive HCC cell proliferation}

PP-10 is a steroidal saponin compound extracted from Paris polyphylla var. yunnanensis (Figure 1A). PP-10 was detected by HPLC and showed only one peak, indicating that the compound was homogenous, with a purity of over 95\% (Figure 1B). We investigated the cytotoxicity of PP- 10 by a screening test using eight human cancer cell lines and one normal cell line. The cell lines were exposed to various concentrations of PP-10 $(0,5,10$, 15 and $20 \mu \mathrm{M}$ ) for $48 \mathrm{~h}$ and the $\mathrm{IC}_{50}$ of the cells was determined by the MTT assay (Figure 1C). PP-10 apparently inhibited the proliferation of HCC cells, including HepG2, HuH7, QGY-7703, Hep 3B, and SMMC-7721, with $\mathrm{IC}_{50}$ values of between $5 \mu \mathrm{mol} / \mathrm{L}$ and $10 \mu \mathrm{mol} / \mathrm{L}$. Among all the tested cells, HepG2 and HuH7 were the most sensitive ones while normal hepatic $\mathrm{LO} 2$ cells were less sensitive than the others by the cytotoxic concentrations of PP-10. These results revealed that PP- 10 treatment selectively suppresses the growth of cancer cells.

We obtained further evidence of the inhibitory effect and cytotoxicity of PP- 10 towards HepG2 and $\mathrm{HuH} 7$ cells by incubating the cells with $0,5,10,15$, and $20 \mu \mathrm{M}$ PP-10 for 24,48 or $72 \mathrm{~h}$, followed by the MTT assay. Cell viability decreased in a dose- and time-dependent manner (Figure 1DE). A colony-formation assay confirmed the anti-proliferation effect of PP-10 on HepG2 and $\mathrm{HuH7}$ cells, with the colony number significantly decreasing as the PP-10 dose increased (Figure 1F). These results suggest that PP-10 inhibits the cell proliferation of HepG2 and $\mathrm{HuH} 7$ in both a dose- and time-dependent manner.

\subsection{PP-10 induces apoptosis of HepG2 and $\mathrm{HuH} 7 \mathrm{cells}$}

Next, the effects of PP-10 on the apoptosis of HCC cells were explored. Hoechst 33258 was used to identify apoptosis by detecting morphological changes (Figure 2A), which included cell shrinkage, chromosomal condensation, and nuclear fragmentation. The Annexin V-FITC/PI double staining assay was used to measure the number of apoptotic cells. Flow cytometry analysis showed that the number of apoptotic cells significantly increased in a dose-dependent manner when HepG2 and HuH7 cells were incubated with PP-10 (Figure 2BC). The percentage of HepG2 and HuH7 apoptotic cells was 18.48\% 

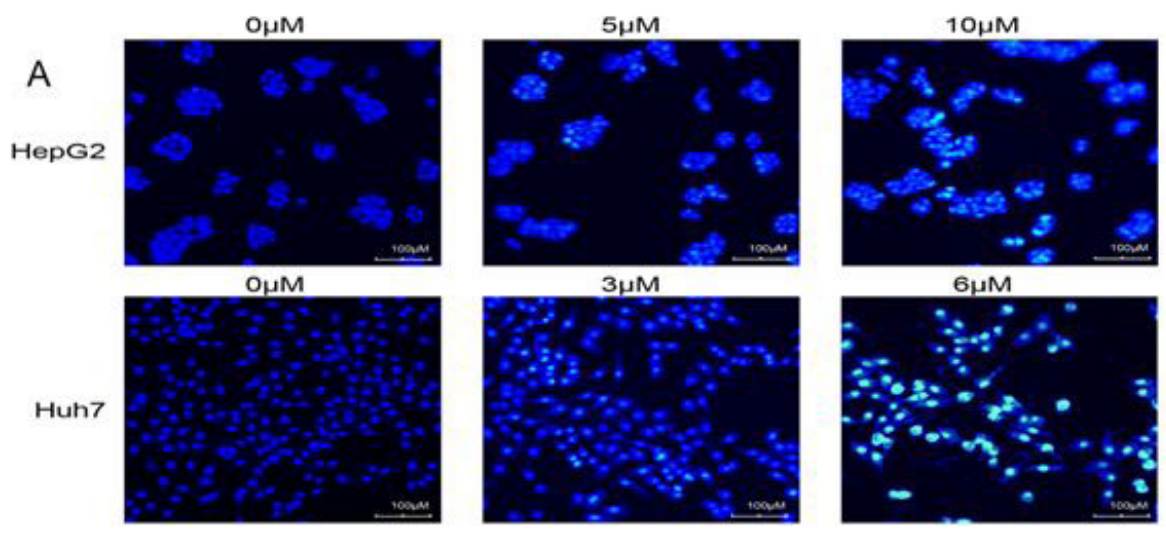

B

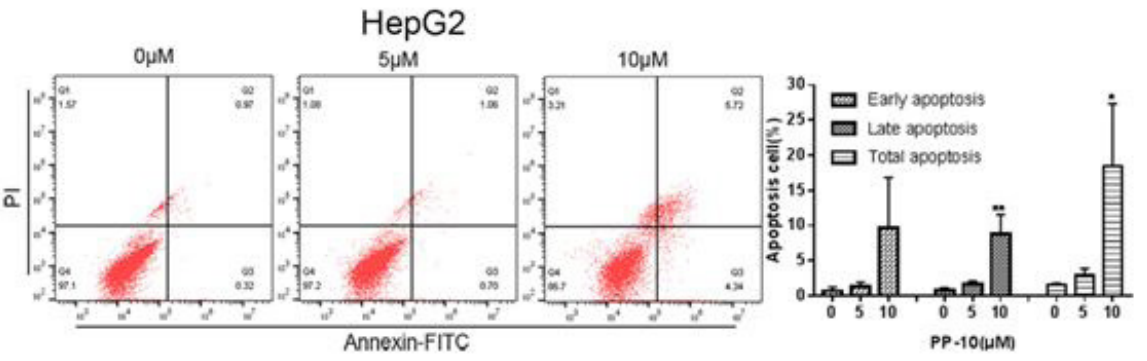

C

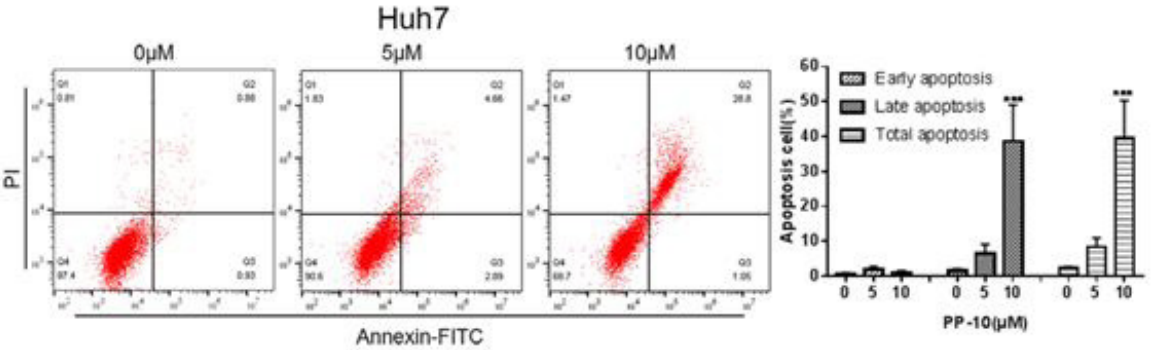

D

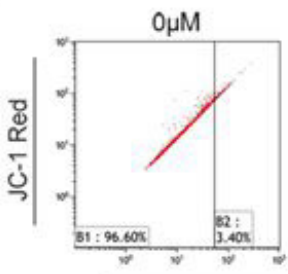

HepG2
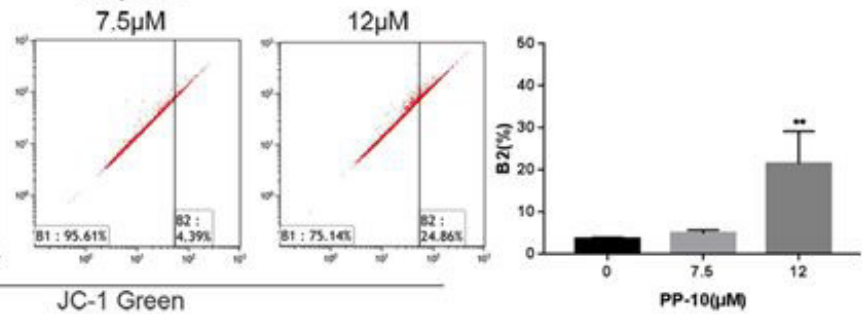

$\mathrm{E}$
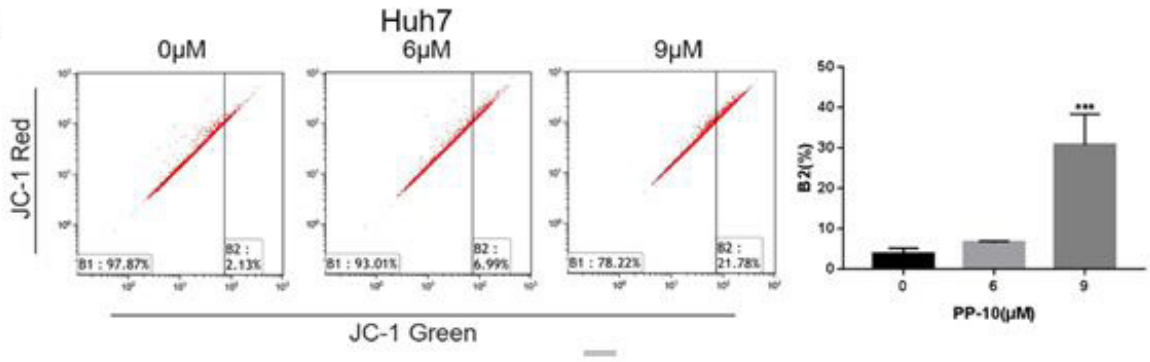

Figure 2. PP-10 induces apoptosis of HepG2 and Huh7 cells. (A-B) The morphological changes of apoptotic nuclear induced by PP-10 were detected by Hoechst33258 stain and observed by fluorescence microscopy. (C-D) The cells apoptosis induced by PP-10 were detected by flow cytometry using the Annexin V-FITC/PI double staining assay. The histograms indicated that the percentage of early apoptosis, late apoptosis and total apoptosis. Numbers indicated the percentage of apoptosis cell in shown as mean \pm SD from three independent experiments. (E-F) The mitochondrial membrane potential were measure using JC-1 staining by flow cytometry. The histogram Y-axis B2 indicated the decreased ratio of mitochondrial membrane potential. The results shown as mean \pm SD from three independent experiments. ${ }^{*}$ compared with control group , $p<0.05 ;^{* *}$ compared with control group $p<0.01{ }^{* * *}$ compared with control group $p<0.001$ (One-way ANOVA). 
and $39.68 \%$, respectively, when exposed to $15 \mu \mathrm{M}$ PP- 10 . Next, we explored whether mitochondria are involved in PP-10-induced apoptosis by testing the mitochondrial membrane potential using the fluorescent mitochondrial probe JC-1. After PP10 treatment, we observed that the percent decrease in the ratio of mitochondrial membrane potential, B2, increased significantly, indicating that PP-10 induces mitochondrial depolarization in HepG2 and HuH7 cells (Figure 2DE).

We further investigated whether PP-10 activates apoptosisassociated protein regulation by examining the expression levels of related proteins using western blotting. We found that the levels of caspase-3, caspase-9, and PARP were decreased, and that the levels of cleaved-3, cleaved-9, and cleaved-PARP were increased (Figure 3ABC) after exposing HepG2 and HuH7 cells to different concentrations of PP-10 for $24 \mathrm{~h}$, whereas the levels of anti-apoptotic Bcl-2 and Bcl-xL were decreased and proapoptotic Bak and Bax were increased (Figure 3DEF). Taken together, these results show that PP-10 induces cell apoptosis by activating the intrinsic apoptosis pathway.

\subsection{PP-10 activates the JNK/SPAK signaling pathway in HepG2 and $\mathrm{HuH7}$ cells}

MAPKS are serine-threonine protein kinases that play important roles in the regulation of cellular processes, including cell growth, cell proliferation, and apoptosis. To further determine the molecular mechanism of apoptosis induced by PP-10, we evaluated whether PP10 induces apoptosis via MAPK activation in HepG2 and HuH7 cells. RNA-seq and GSEA analysis results showed that MAPK pathway genes were significantly enriched in PP-10-treated HEPG2 and $\mathrm{HuH} 7$ cells compared with the control treatment group, suggesting that PP-10 can significantly activate the MAPK signaling pathway (Figure 4AB).

We validated the changes in the expression levels of MAPKS signaling pathway proteins. After HepG2 and $\mathrm{HuH} 7$ cells were exposed to the indicated concentrations of PP-10 for $24 \mathrm{~h}$, the expression levels of phosphorylated JNK ( $\mathrm{p}$-JNK) protein were obviously elevated but the protein expression levels of $\mathrm{p}$-ERK and p-p38 remained unchanged. Furthermore, the expression levels of c-JUN were increased (Figure 4CDEF). These results show that the JNK/SPAK signaling pathway was activated by PP-10 and induced apoptosis in Hepg2 and HuH7 cells.

\subsection{PP-10 inhibits STAT3 activity and its downstream signaling pathway}

STAT3 plays crucial roles in cell proliferation. We demonstrated that PP-10 inhibits cell proliferation by targeting STAT3 by determining the levels of STAT3 and its downstream proteins using western blotting. As shown in Figure 5AB, STAT3 signaling pathways were inhibited. The expression levels of p-STAT3, total STAT3, and its downstream proteins c-Myc, Mcl-1, CyclinD1, and $\mathrm{Bcl}-2$, all decreased markedly in a dose-dependent manner. We verified these results by pretreating the cells with SH5-07 (a STAT3 inhibitor) for $2 \mathrm{~h}$ before the $24 \mathrm{~h}$ treatment with PP10. Western blotting analysis revealed that SH5-07 decreased the expression of STAT3 and p-STAT3 compared with the control treatment with SH5-07. Moreover, suppression of the downstream proteins CyclinD1 and $\mathrm{Mcl}-1$ was enhanced by
SH5-07 (Figure 5CD). These data showed that PP-10 can induce apoptosis by inhibiting STAT3 signaling.

\section{Discussion}

Hepatocellular carcinoma (HCC) is among the most challenging types of malignant tumor to treat. Because there are few symptoms until later stages of the disease, it is often diagnosed at advanced stages (Yang et al., 2009). Classical chemotherapy still plays an important role in the treatment of advanced HCC but most chemotherapeutics have little effect and only a few have shown clinical benefits. At the same time, the side effects of chemotherapy and multi-drug resistance affect therapeutic outcomes (Yuan et al., 2017). In contrast, natural products have rich structural diversity and are promising therapeutics for the prevention and treatment of cancer and thus attract increasing attention (Clardy \& Walsh, 2004). Several compounds isolated from Paris polyphylla have been reported to have considerable antitumor effects on various kinds of cancer cells. For example, Paris polyphylla ethanol extract exhibits an anti-cancer effect by inducing cancer cell apoptosis and cell cycle arrest in prostate cancer cells (Zhang et al., 2018), steroidal saponins from Paris polyphylla induce apoptotic cell death and autophagy in A549 human lung cancer cells (He et al., 2015), and we previously confirmed that PP-22, a compound also isolated from Paris polyphylla var. yunnanensis, promotes autophagy and apoptosis in nasopharyngeal carcinoma cells (Tan et al., 2019). These results suggest that extracts of Paris polyphylla could profoundly impact our understanding of cancer therapy. To date, our research group has obtained a series of compounds isolated from Paris polyphylla var. yunnanensis. The anti-tumor effects and underlying mechanism of action of PP-10 have not previously been studied and thus were investigated here using HCC cell lines. The results showed that PP-10 inhibits cell proliferation and induces apoptosis via the JNK/SPAK and STAT3 signaling pathways in HCC cells.

We found that PP-10 was cytotoxic towards various cancer cell lines but had no effect on LO2 human hepatic immortal cells. Among the cancer cell lines tested, HepG2 and HuH7 HCC cells were especially sensitive to PP-10, and PP-10 inhibited the growth of HepG2 and HuH7 cells in a concentration- and time-dependent manner. We concluded that PP-10 inhibits HepG2 and HuH7 hepatoma carcinoma cell growth (Figure 1).

Apoptosis is a cellular process regulated by different groups of executioner and regulatory molecules (Mukhopadhyay et al., 2014) and abnormal behavior of these molecules is fundamental to tumor growth and cancer development (Goldar et al., 2015). Thus, many studies are conducted to explore the therapeutic potential of regulating the molecular targets involved in apoptosis. Here, we explored whether PP-10 induces apoptosis in the human HCC cell lines HepG2 and HuH7 through mitochondria-dependent signaling pathways, primarily using Hoechst 33258 and the Annexin V-FITC/PI double staining assay to verify cell apoptosis. The results showed that PP-10 causes morphological changes in hepatoma carcinoma cells and induced early and later stage apoptosis. We also observed a significant decrease in mitochondrial membrane potential, allowing activation of the intrinsic apoptosis pathway. The caspase family and Bcl-2 family are important 

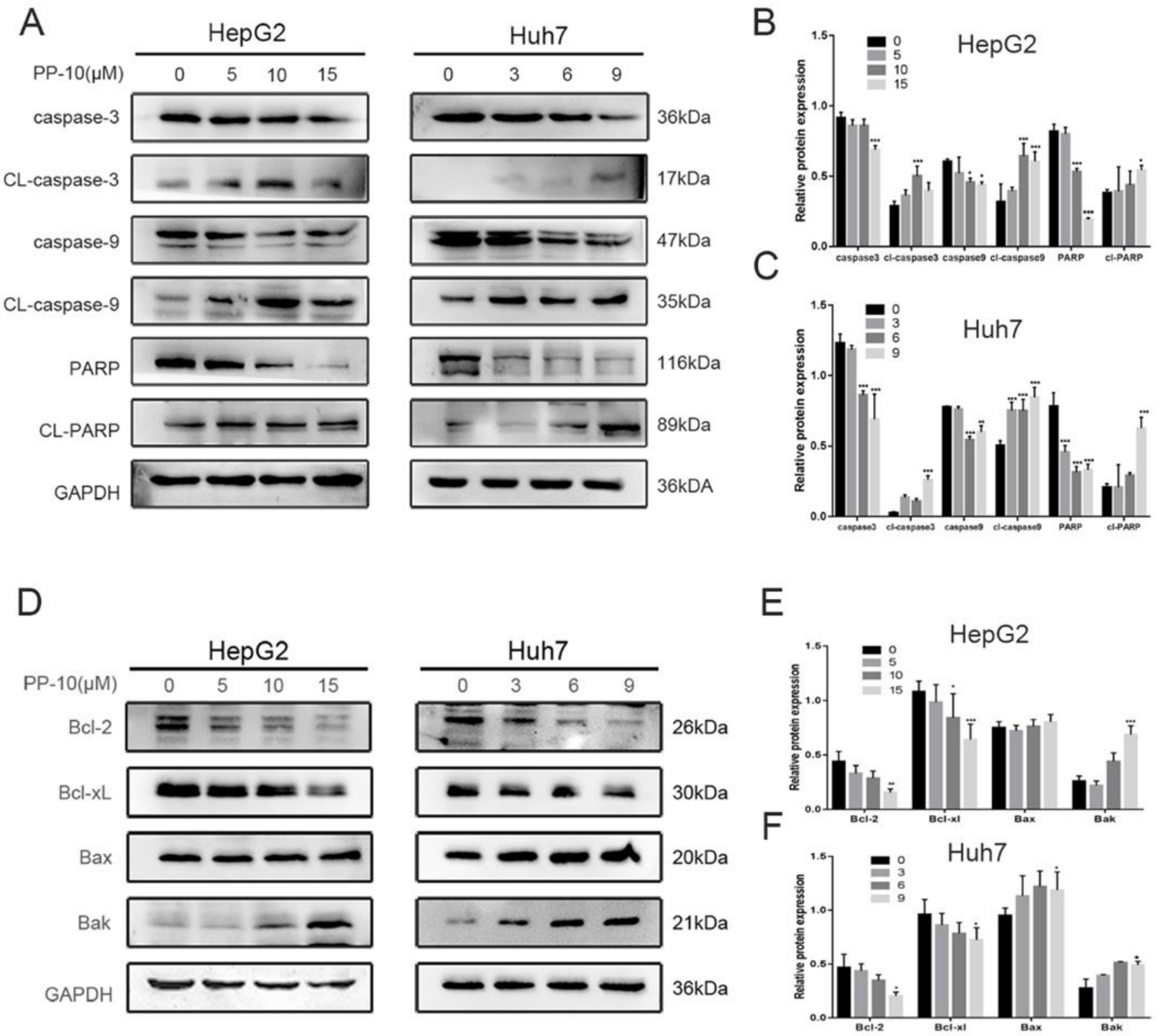

Figure 3. PP-10 induces apoptosis of HepG2 and Huh7 cells in protein levels. (A-F) Western blotting analyzed the expression levels of caspase-3, caspase-9,cleaved caspase-3, cleaved caspase-9, PARP, cleaved PARP, Bcl-2, Bcl-xl, Bak, Bax and GAPDH. HepG2 cells were treated with PP$10(0,5,10,15 \mu \mathrm{M})$ for $24 \mathrm{~h}$ and Huh7 were treated with PP-10 $(0,3,6,9 \mu \mathrm{M})$ for $24 \mathrm{~h}$. The histograms data were express as mean \pm S.D. of three independent experiments. ${ }^{*}$ compared with control group , $p<0.05 ;{ }^{* *}$ compared with control group $p<0.01$; ${ }^{* *}$ compared with control group $p<0.001$ (Two- way ANOVA).

components of mitochondria-dependent apoptosis pathways (Sun et al., 2008). Our results indicate that incubation with PP-10 resulted in activation of caspase-9, caspase-3, and PARP, as well as a decrease in the levels of the anti-apoptotic protein Bcl-2 and an increase in the levels of the pro-apoptotic protein Bak. These results demonstrated that PP-10 induced apoptosis in hepatoma carcinoma cells by activating mitochondria-dependent apoptotic pathways.

We further explored the mechanism of PP-10-induced apoptosis in HepG2 and HuH7 HCC cells. It is well known that the MAPK pathway is a potential target in the therapy of various malignancy cancers due to its capacity to regulate cell apoptosis and proliferation (Bahrami et al., 2017). The MAPK signaling pathway is a widely distributed protein kinase pathway and can be subdivided into four subtypes ERK, p38, JNK( Eriksson et al., 2017), and ERK5. We focused on the MAPK pathway while conducting GSEA on hepatoma cell samples. The results showed that PP-10 induced apoptosis in the drug treatment group. JNK, as an important branch of the MAPK pathway, may be activated by different environmental stresses such as oxidative stress and chemical reagents. The JNK/SPAK signaling pathway plays an important role in apoptosis. In the present study, we observed 
A

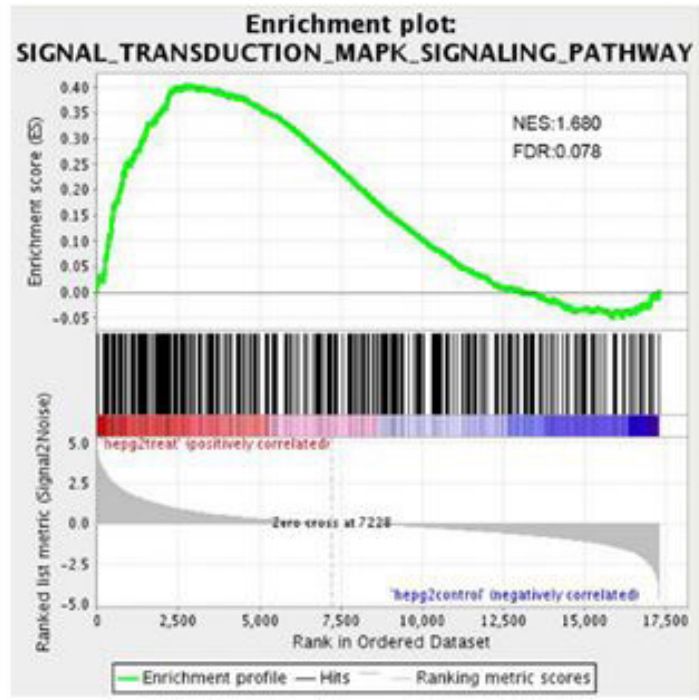

C

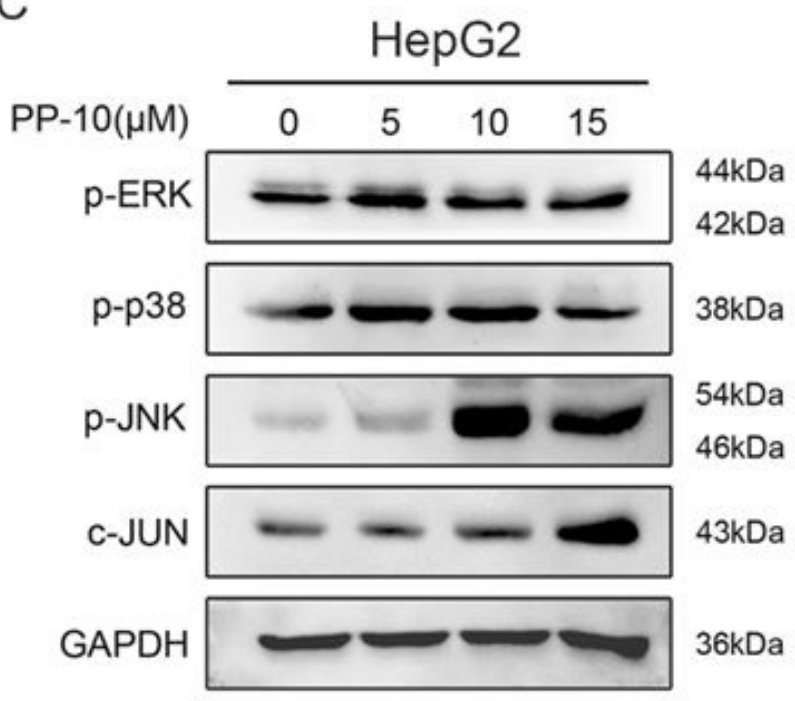

$E$

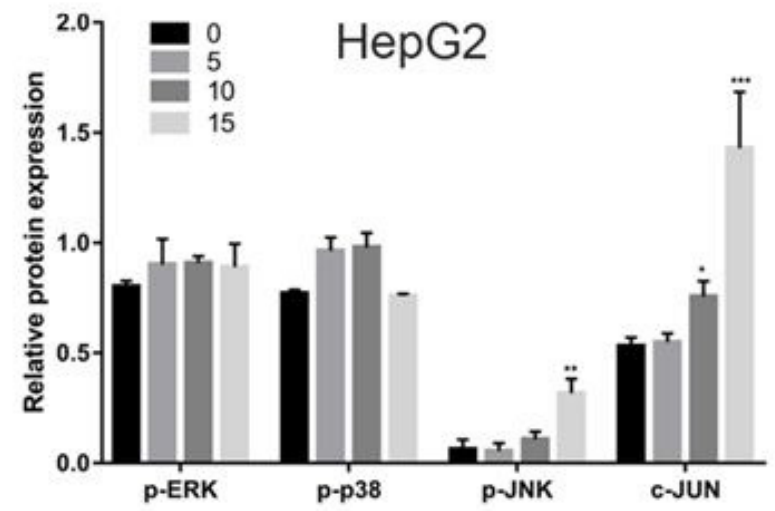

B Enrichment plot: SIGNAL_TRANSDUCTION_MAPK_SIGNALING_PATHWAY

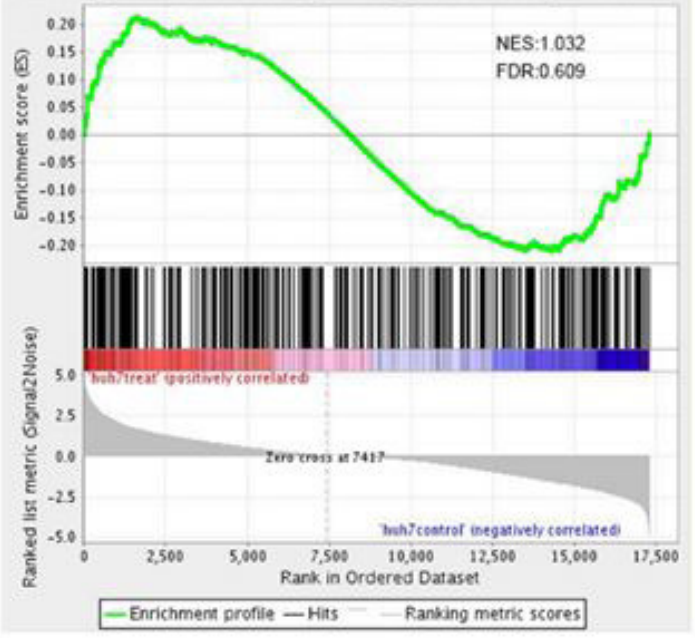

D

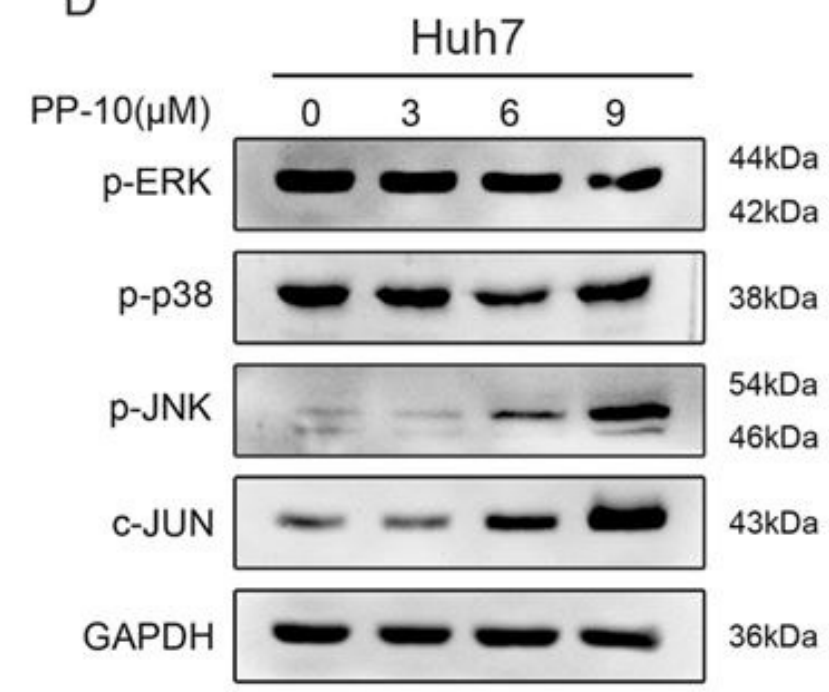

$\mathrm{F}$

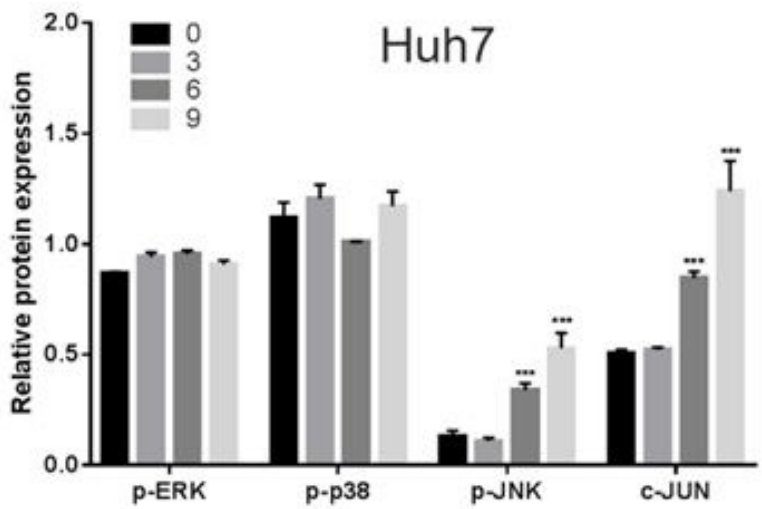

Figure 4. PP-10 activates JNK/SPAK signaling pathway in HepG2 and Huh7 cells. (A-B) Gene set enrichment analysis (GSEA) showed that PP10 could significantly activate MAPK apoptosis pathway in HepG2 and Huh7 cells. (C-F) After the indicated concentration of PP-10 treatment, Western blotting was demonstrated to analyze the protein levels of phosphorylated MAPK member (p-JNK, p-p38, p-ERK) and c-JUN. The histograms data were express as mean \pm S.D. of three independent experiments. ${ }^{*}$ compared with control group , $p<0.05 ;{ }^{* *}$ compared with control group $p<0.01 ;{ }^{* *}$ compared with control group $p<0.001$ (Two- way ANOVA). 
A

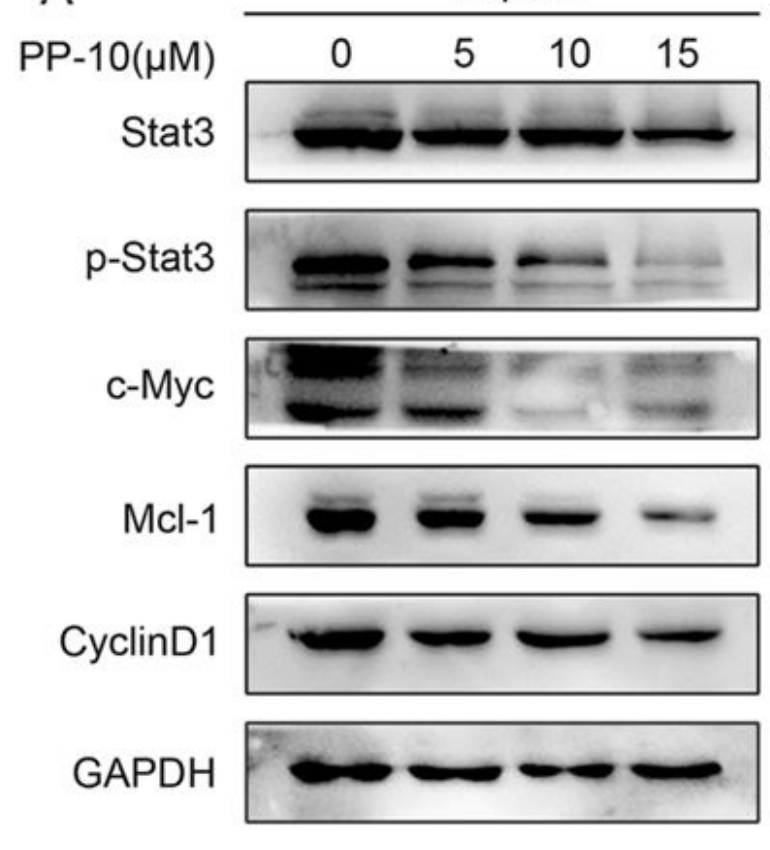

C

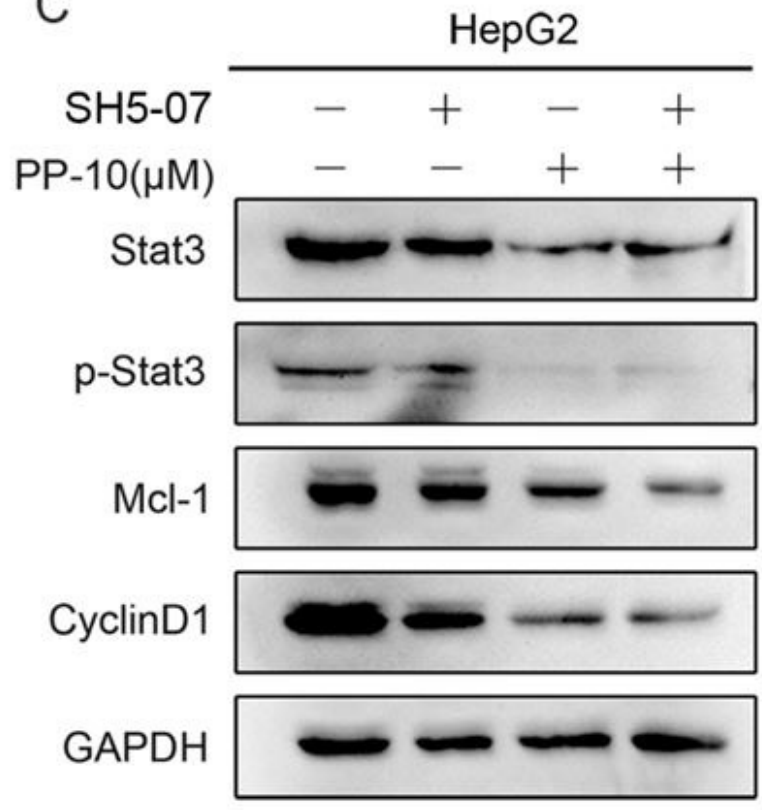

B

$79 \mathrm{kDa}$
$86 \mathrm{kDa}$
$79 \mathrm{kDa}$
$86 \mathrm{kDa}$

$57 \mathrm{kDa}$

$35 \mathrm{kDa}$

$36 \mathrm{kDa}$

$36 \mathrm{kDa}$

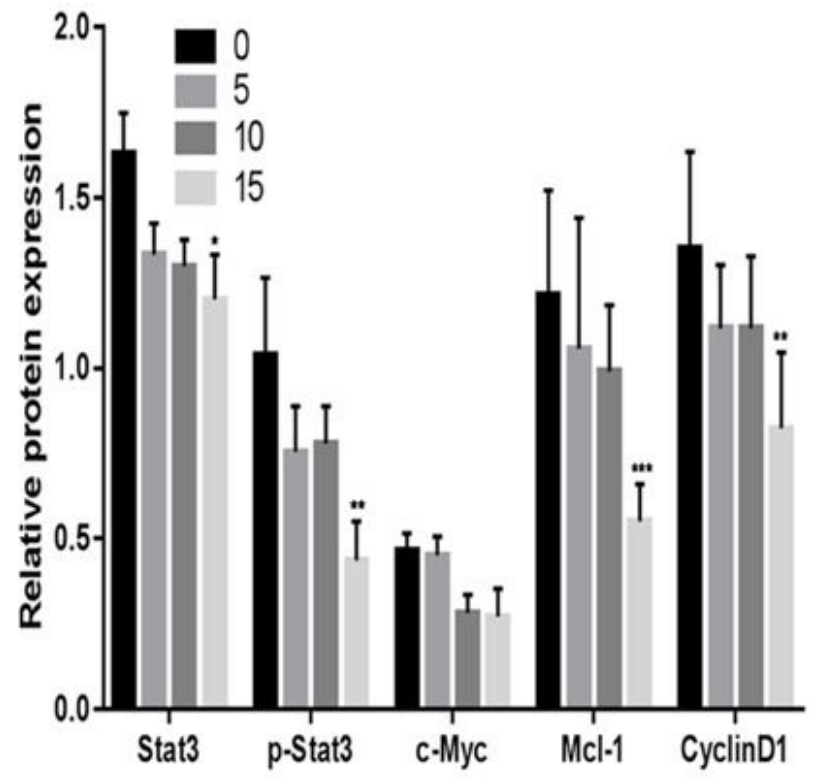

D

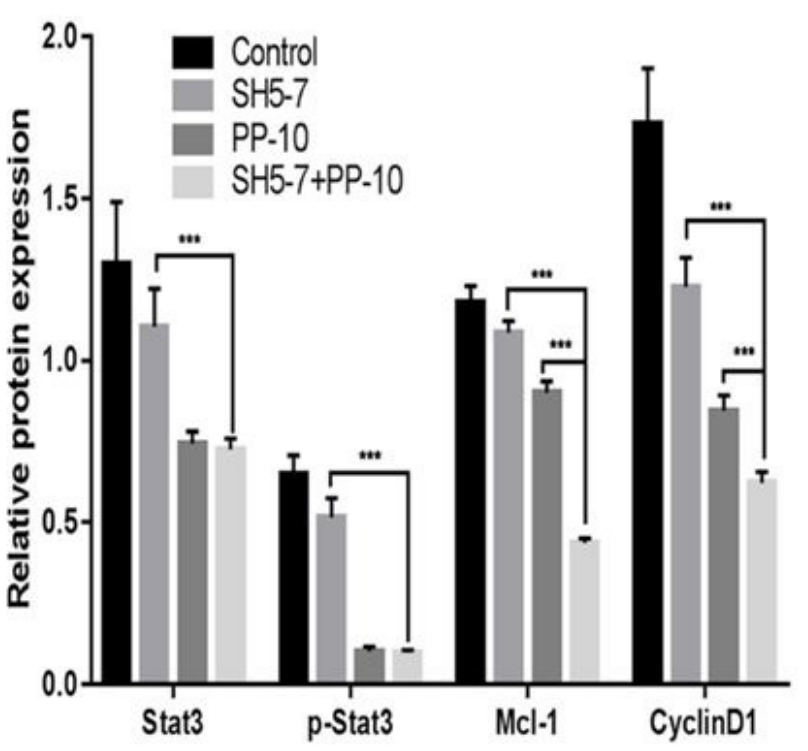

Figure 5. PP-10 inhibits STAT3 activity and its downstream signaling pathway. (A-B) HepG2 cells were treated with indicated concentration of PP-10 for 24h. Western blotting was analyzed the protein levels of STAT3 and its downstream proteins. The histograms data were express as mean \pm SD of three independent experiments. (C-D) After pretreated 10 $\mu \mathrm{M}$ SH5-07 of STATS3 inhibitor for 2h, HepG2 cells were treated with or without $10 \mu \mathrm{M}$ PP-10 for $24 \mathrm{~h}$. Western blotting was analyzed the protein levels of STAT3 and its downstream proteins. The histograms data were express as mean \pm SD of three independent experiments. ${ }^{*}$ compared with control group, $p<0.05$; ${ }^{* *}$ compared with control group $p<0.01$; ${ }^{* * *}$ compared with control group $p<0.001$ (Two- way ANOVA).

that the expression levels of $\mathrm{p}$-JNK and its downstream protein c-JUN were clearly increased in HepG and HuH7 HCC cells, suggesting that PP-10 induces apoptosis by activating the MAPK/ JNK/c-JUN signaling pathway in HepG2 and HuH7 cells.
Signal transducer and activator of transcription 3 (STAT3) is a transcription factor that regulates the expression of genes related to the cell cycle, cell survival, and immune response associated with cancer progression and malignancy in manifold cancer types. 


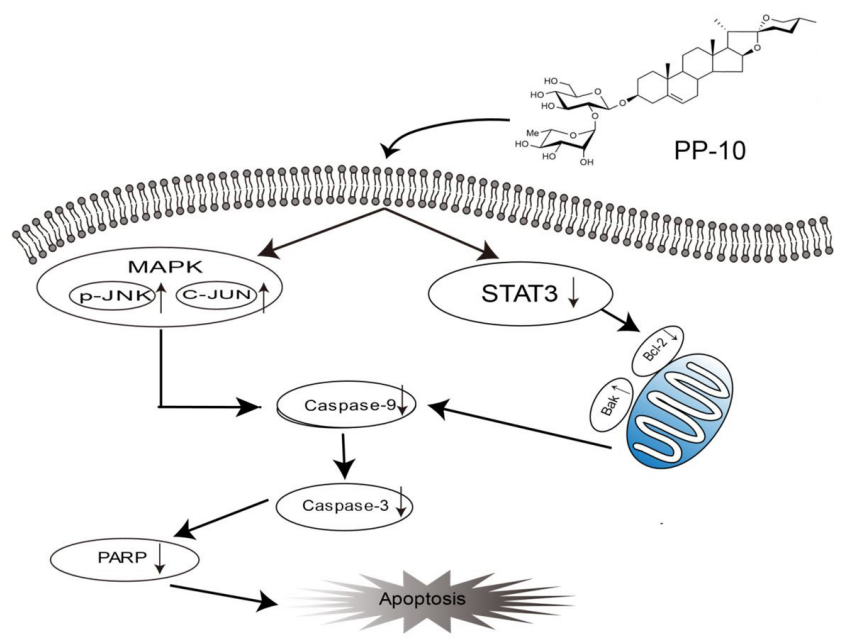

Figure 6. The schematic graph demonstrating the underlying mechanism of PP-10 induce apoptosis in hepatocellular carcinoma cells. PP-10 activated JNK/SPAK and inhibited STAT3 pathway to activate the caspse-9/3 pathway to induce apoptosis in hepatocellular carcinoma cells.

It has been reported that human solid and hematological tumors display overexpression or constitutively active STAT3 compared with normal cells (Furtek et al., 2016). Furthermore, inhibition of the STAT3 signaling pathway may induce cell apoptosis. Thus, the STAT3 pathway is a promising drug target for cancer therapies. The focus of our study was to verify that PP-10 induces apoptosis by inhibiting the STAT3 signaling pathway. Our results demonstrate that PP-10 inhibits p-STAT3 and the downstream STAT3 proteins c-Myc, Mcl-1, CyclinD1, and Bcl-2. SH5-07, a STAT3 inhibitor, increased the PP-10-mediated suppression of Mcl-1 and CyclinD1 expression, showing that PP-10 induces HepG2 cell apoptosis by inhibiting the STAT3 pathway.

In summary, our study demonstrated the antitumor effect and mechanism of action of PP-10 on hepatoma carcinoma cells. PP-10 induces apoptosis of hepatocellular carcinoma cells by regulating the JNK/SPAK and STAT3 signaling pathways. Thus, PP-10 is a potential drug for the treatment of human liver cancer (Figure 6).

\section{Conclusion}

Collectively, our results show that PP-10 induces apoptosis via the JNK/SPAK and STAT3 signaling pathways in HepG2 and HuH7 hepatocarcinoma cells. PP-10 may be a promising agent for the treatment of liver cancer.

\section{Conflict of interest}

The author reports no conflicts of interest in this work.

\section{Acknowledgements}

The work was supported by the Science and Technology Planning Project of Guangdong Province, Grant No. 2018B030320007; Science and Technology Planning Project of Guangzhou, China, Grant/Award No. 201607010372; and the National Natural Science Foundation of China, Grant No. 81673319 .

\section{References}

Bahrami, A., Hasanzadeh, M., Hassanian, S. M., ShahidSales, S., Ghayour-Mobarhan, M., Ferns, G. A., \& Avan, A. (2017). The potential value of the PI3K/Akt/mTOR signaling pathway for assessing prognosis in cervical cancer and as a target for therapy. Journal of Cellular Biochemistry, 118(12), 4163-4169. http://dx.doi. org/10.1002/jcb.26118. PMid:28475243.

Clardy, J., \& Walsh, C. (2004). Lessons from natural molecules. Nature, 432(7019), 829-837. http://dx.doi.org/10.1038/nature03194. PMid:15602548.

Eriksson, M., Pena-Martinez, P., Ramakrishnan, R., Chapellier, M., Högberg, C., Glowacki, G., Orsmark-Pietras, C., Velasco-Hernández, T., Lazarević, V. L., Juliusson, G., Cammenga, J., Mulloy, J. C., Richter, J., Fioretos, T., Ebert, B. L., \& Järås, M. (2017). Agonistic targeting of TLR1/TLR2 induces p38 MAPK-dependent apoptosis and NFkappaBdependent differentiation of AML cells. Blood Advances, 1(23), 2046-2057. http://dx.doi.org/10.1182/bloodadvances.2017006148. PMid:29296851.

Forner, A., Reig, M., \& Bruix, J. (2018). Hepatocellular carcinoma. Lancet, 391(10127), 1301-1314. http://dx.doi.org/10.1016/S01406736(18)30010-2. PMid:29307467.

Furtek, S. L., Backos, D. S., Matheson, C. J., \& Reigan, P. (2016). Strategies and approaches of targeting STAT3 for cancer treatment. ACS Chemical Biology, 11(2), 308-318. http://dx.doi.org/10.1021/ acschembio.5b00945. PMid:26730496.

Goldar, S., Khaniani, M. S., Derakhshan, S. M., \& Baradaran, B. (2015). Molecular mechanisms of apoptosis and roles in cancer development and treatment. Asian Pacific Journal of Cancer Prevention, 16(6), 2129-2144. http://dx.doi.org/10.7314/APJCP.2015.16.6.2129. PMid:25824729.

Hao, Q., Han, Y., Xia, W., Wang, Q., \& Qian, H. (2019). Systematic review and meta-analysis of the utility of circular RNAs as biomarkers of hepatocellular carcinoma. Canadian Journal of Gastroenterology \& Hepatology, 2019, 1684039. http://dx.doi.org/10.1155/2019/1684039. PMid:31187026.

He, H., Sun, Y. P., Zheng, L., \& Yue, Z. G. (2015). Steroidal saponins from Paris polyphylla induce apoptotic cell death and autophagy in A549 human lung cancer cells. Asian Pacific Journal of Cancer Prevention, 16(3), 1169-1173. http://dx.doi.org/10.7314/APJCP.2015.16.3.1169. PMid:25735350.

Ikeda, M., Morizane, C., Ueno, M., Okusaka, T., Ishii, H., \& Furuse, J. (2018). Chemotherapy for hepatocellular carcinoma: current status and future perspectives. Japanese Journal of Clinical Oncology, 48(2), 103-114. http://dx.doi.org/10.1093/jjco/hyx180. PMid:29253194.

Liang, M. Y., Wang, Y.Z., Qiao, X., Lu, Y. W., Chen, M. H., Li, P., Wen, X. D., \& Yang, J. (2019). Structural characterisation and discrimination of the aerial parts of Paris polyphylla var. yunnanensis and Paris polyphylla var. chinensis by UHPLC-QTOF-MS coupled with multivariate data analysis. Phytochemical Analysis, 30(4), 437-446. http://dx.doi.org/10.1002/pca.2826. PMid:30816611.

Ling, C. Q., Fan, J., Lin, H. S., Shen, F., Xu, Z. Y., Lin, L. Z., Qin, S. K., Zhou, W. P., Zhai, X. F., Li, B., \& Zhou, Q. H. (2018). Clinical practice guidelines for the treatment of primary liver cancer with integrative traditional Chinese and Western medicine. Journal of Integrative Medicine, 16(4), 236-248. http://dx.doi.org/10.1016/j. joim.2018.05.002. PMid:29891180. 
Morales-Ávila, U. M., Becerra-Verdín, E. M., Sáyago-Ayerdi, S. G., Tolman, J. P., \& Montalvo-González, E. (2020). Anti-obesity and hepatoprotective effects in obese rats fed diets supplemented with fruit purees. Food Science and Technology, 40(Suppl. 1), 33-41. http:// dx.doi.org/10.1590/fst.31618.

Mostafa, H. S., Ali, M. R., \& Mohamed, R. M. (2021). Production of a novel probiotic date juice with anti-proliferative activity against Hep-2 cancer cells. Food Science and Technology, 41(Suppl. 1), 105115. http://dx.doi.org/10.1590/fst.09920.

Mukhopadhyay, S., Panda, P. K., Sinha, N., Das, D. N., \& Bhutia, S. K. (2014). Autophagy and apoptosis: where do they meet? Apoptosis, 19(4), 555-566. http://dx.doi.org/10.1007/s10495-014-0967-2. PMid:24415198.

Sia, D., Villanueva, A., Friedman, S. L., \& Llovet, J. M. (2017). Liver cancer cell of origin, molecular class, and effects on patient prognosis. Gastroenterology, 152(4), 745-761. http://dx.doi.org/10.1053/j. gastro.2016.11.048. PMid:28043904.

Song, Y., Wang, S., Ding, Y., Xu, J., Li, M. F., Zhu, S., \& Chen, N. (2017). Chloroplast genomic resource of paris for species discrimination. Scientific Reports, 7(1), 3427. http://dx.doi.org/10.1038/s41598-01702083-7. PMid:28611359.

Sun, J., Li, Z. M., Hu, Z. Y., Lin, X. B., Zhou, N. N., Xian, L. J., Yang, D. J., \& Jiang, W. Q. (2008). ApoG2 inhibits antiapoptotic Bcl-2 family proteins and induces mitochondria-dependent apoptosis in human lymphoma U937 cells. Anti-Cancer Drugs, 19(10), 967-974. http:// dx.doi.org/10.1097/CAD.0b013e32831087e8. PMid:18827561.

Tan, G. X., Wang, X. N., Tang, Y. Y., Cen, W. J., Li, Z. H., Wang, G. C., Jiang, J. W., \& Wang, X. C. (2019). PP-22 promotes autophagy and apoptosis in the nasopharyngeal carcinoma cell line CNE-2 by inducing endoplasmic reticulum stress, downregulating STAT3 signaling, and modulating the MAPK pathway. Journal of Cellular Physiology, 234(3), 2618-2630. http://dx.doi.org/10.1002/jcp.27076. PMid:30191969.

Wang, J., \& Jin, D. (2021). Study on the mechanism and therapeutic effect of Antelope horn treatment on cerebral ischemia reperfusion injury of mouse. Food Science and Technology, 41(Suppl. 1), 142-149. http://dx.doi.org/10.1590/fst.35119.

Yan, Z., Lai, Z., \& Lin, J. (2017). Anticancer properties of traditional Chinese medicine. Combinatorial Chemistry \& High Throughput Screening, 20(5), 423-429. http://dx.doi.org/10.2174/13862073206 66170116141818. PMid:28093974.

Yang, S. L., Liu, X. K., Wu, H., Wang, H. B., \& Qing, C. (2009). Steroidal saponins and cytoxicity of the wild edible vegetable-smilacina atropurpurea. Steroids, 74(1), 7-12. http://dx.doi.org/10.1016/j. steroids.2008.08.008. PMid:18817798.

Yuan, R., Hou, Y., Sun, W., Yu, J., Liu, X., Niu, Y., Lu, J. J., \& Chen, X. (2017). Natural products to prevent drug resistance in cancer chemotherapy: a review. Annals of the New York Academy of Sciences, 1401(1), 19-27. http://dx.doi.org/10.1111/nyas.13387. PMid:28891091.

Zhang, D., Li, K., Sun, C., Cao, G., Qi, Y., Lin, Z., Guo, Y., Liu, Z., Chen, Y., Liu, J., Cheng, G., Wang, P., Zhang, L., Zhang, J., Wen, J., Xu, D., Kong, F., \& Zhao, S. (2018). Anti-cancer effects of paris polyphylla ethanol extract by inducing cancer cell apoptosis and cycle arrest in prostate cancer cells. Current Urology, 11(3), 144-150. http://dx.doi. org/10.1159/000447209. PMid:29692694. 